International Journal of Ambient Systems and Applications (IJASA) Vol.1, No.2, June 2013

\title{
APPLICATION OF ANDROID ENABLED MOBILE DEVICE For PERSONAL INFORMATION SYSTEMS
}

\author{
Duarte-Rhian Nicely $^{1}$ and Suresh Sankaranarayanan ${ }^{2,3}$ \\ ${ }^{1}$ Department of Computing, University of WestIndies, Kingston, Jamaica \\ rhian16@gmail.com \\ ${ }^{2}$ Computing and Information Systems, Institut Teknologi Brunei, Brunei \\ ${ }^{3}$ Department of Computing, University of WestIndies, Kingston, Jamaica \\ pessureshehotmail.com
}

\begin{abstract}
The advent of Mobile technology is indicative of an era in which society requires the transfer of information via a medium that facilitates mobility. Therefore, it is widely accepted that Mobile Information Systems have been in use in a number of situations where access to information is required while on the move. However, deeper analysis has revealed that mobile information systems are mainly concerned with providing generic information to users without much scope for customization.

This has created a need to develop what is called Personal Information Systems. It can be viewed as an empowering tool for users based on their input into the system as they can enhance the level of information supplied to them. At the same time due to travel patterns and the availability of modern transportation facilities, people have become dependent on 'GPS navigation and route planners/maps to move from one location to the other. With the rapid development of the Android platform, there are a number of services that can be incorporated into Personal Mobile Information Systems using GPS that have not been fully explored. The combination of mobile device technology and information systems to create a personal mobile information system still poses a number of challenges for the creation of useful applications. The development of a Personal Information System that at least takes all these issues into consideration is therefore needed in order to create a balance between design, functionality, and security of the users' data during transmission.

Location Based Services (LBS) is a key functionality in smart phone applications that is often combined with maps to enhance the user experience about their location.

With all that has been said the proposed research here presents a Personal Mobile Information System (PMIS) developed on the Android platform that provides Location Based Services in the form of GPS enabled proximity alerts, and a rating system including security rating for a point of interest (POI) provided on the application which is novel and an extension of Mobile Information System. The proposed system will also contain features that will plot a route from the user's current location to the point of interest. Based on security data provided by police authority sources, if at any point along the route there is a crime or high alert situation that has been logged, the user will be informed by way of a proximity alert which is another novelty of system.
\end{abstract}

\section{KEYWORDS}

GPS, LBS, PMIS, POI, Android

\section{INTRODUCTION}

Information has been playing an increasingly important role in our society. It is used to facilitate our activities and decision making on a daily basis. Information in and of itself would be useless if there were no medium for it to be transferred. Therefore, the advent of the computer and even more the internet has further played critical roles in cementing information as the single most important commodity of this current era [1]. We can identify many instances in which these tools of information are being utilized in new and innovative ways like Business, Social networking, Crime and so forth.

DOI : $10.5121 /$ ijasa.2013.1201 
International Journal of Ambient Systems and Applications (IJASA) Vol.1, No.2, June 2013

As it is clear that for information to be transferred, there is need of medium and which in today's era is mobile which is very much prevalent with everyone with the advent of Mobile Technology today. So it is widely accepted that Mobile Information Systems have been in use in a number of situations where access to information is required while on the move [2]. These include mobile learning, GPS navigation, road weather information, mobile shopping. Such services provide a wealth of information that is useful to users; hence there is a great demand for mobile information systems in the mobile technology market. However, deeper analysis has revealed that mobile information systems are mainly concerned with providing generic information to users without much scope for customization. This has created a need to develop what is called Personal Information Systems, which are designed to cater to specific needs of the consumer whether explicitly stated by them or inferred by the system depending on the information gathered overtime [3]. In other words, personalized solutions are built on the foundation of Mobile Information Systems by making the various services available more useroriented.

This concept makes sense, if we consider the diverse cultural, social, and economic situation of people across the globe, but having access to the same applications. Even within the same geographic location, there may be differing views and attitudes that exist among the population. Based on this logic, not all information provided will appeal to everyone. Therefore, personal information systems can be viewed as an empowering tool for users based on their input into the system; they can enhance the level of information supplied to them. This notion was captured by researchers [2] who's development of a personal information system focused on providing users with information on prominent attractions/ places of interest and allow them to rate such attractions based on selected categories including safety, cleanliness and quality of service. The developers also pointed out that due to travel patterns and the availability of modern transportation facilities; people have become dependent on 'GPS navigation and route planners/maps to move from one location to the next'. Most mobile devices on the technology market today are already equipped with GPS functionality. However, with the rapid development of the Android platform, there are a number of services that can be incorporated into Personal Mobile Information Systems using GPS that have not been fully explored.

So accordingly the proposed system developed in Android environment seeks to create a Personal Mobile Information System (PMIS) that provides Location based Services in the form of GPS enabled proximity alerts, and a rating system including security rating for a point of interest provided on the application which is an unique and improvement over Mobile Information System [2] with an emphasis on safety for users as they move from one location to the other. In addition system will plot a route from the user's current location to the point of interest. Based on security data provided by police authority sources, if at any point along the route there is a crime or high alert situation that has been logged, the user will be informed by way of a proximity alert. These details are explained in forthcoming sections. Section 2 talks on Literature survey on Personal Mobile Information System and GPS navigation. Section 3 talks on System architecture developed towards Personal Mobile Information system in Android followed by users functionalities and use case diagram. Section 4 talks on implementation using Android. Section 5 talks on Conclusion and Future work.

\section{Personal Mobile Information Systems}

This section here gives a detailed literature survey on Personal Mobile Information Systems followed by GPS

\subsection{Overview of Personal Mobile Information Systems}

Personal Mobile Information Systems were designed to gather and supply unique information to each user depending on their situation, taste or needs. However, such facilities can only be 
International Journal of Ambient Systems and Applications (IJASA) Vol.1, No.2, June 2013

delivered if particular techniques are adopted in the design of the system. One author in his research [3] highlights this point clearly by stating the different types of personalization techniques that are normally considered in the design of personal information systems. The four main groups that influence personalization are listed as follows:

- 'User factors- the interests of users, their preferences, and characteristics;

- Information or content factors- Properties of the information, e.g. the media type, the life span of the information and whether there is content and / or associated meta data;

- Context factors- The environment of the personalized information system and its user, e.g. the current location;

- Retrieval approaches- There are different types of information retrieval approaches from a user's point of view which also influence the design (e.g. querying and browsing are different types of information retrieval).' [3]

Essentially, personal information systems must reflect the interest of the user whether directly or indirectly expressed in order to provide information that meets their requirements. Similarly, in another source [4], that speaks to personal information systems, it explains, 'mobile applications often aim to context-awareness, the ability of the application to extract, interpret and use situational information and adapt functionality to the current context of use'. It goes to states some examples of context information namely identity; spatial information such as location; temporal information such as time of day, season of the year, environmental information such as temperature, air quality, social information such as who you are with or people that are nearby; schedules and agendas and so on

\subsection{GPS Navigation and Personal Information Systems}

In a study entitled 'A Mobile Location-based Information Recommendation System based on GPS and Web 2.0 Services'. One of the researcher [5] points out that the typical location based services involve GPS to derive information from single content providers such as telecommunication service providers. Researchers [5] set out to develop a system that brought together location based services with more real-time, and targeted content services through Web 2.0 applications. Examples are blogs and forums to address that issue. They pointed out that filtering the users' value added data would be an important element of the system in order to maintain the relevance of the information or to ensure that only information of interest is supplied to users. In connection to this, the proposed solution will also be keen on including more real-time data to inform the decisions of users.

One of the researcher highlights the merits in using GPS with maps in Personal Information System. He states by using GPS coordinates, appropriate software can perform all manner of tasks, from locating the unit, to finding a route from A to B, or dynamically selecting the best route in real time. These systems need to work with map data, which does not form part of the GPS system. The availability of high powered computers in small, portable packages has led to a variety of solutions which combines maps with location information to enable the user to navigate'. All these functionalities revealed by the literature can be supported by the latest Android technology [6]. The main advantage being it supports map layering for easy annotations

\subsection{Mobile Information Systems}

Mobile information systems have been in use in a number of situations where access to information is required while on the move and some of these include mobile learning, GPS navigation, road weather information, mobile shopping, etc. As these systems provide more common information, they don't cater more towards personalized information. This fact has 
International Journal of Ambient Systems and Applications (IJASA) Vol.1, No.2, June 2013

now given rise to the need for what we call the personal information systems. It is with such requirements in view, a Personal Mobile Information System has already been developed using Java 2Micro Edition (J2ME) on mobile devices [2] that would provide the user with information about prominent attractions (restaurants, shopping malls, clubs, etc) of his choice, in a selected geographic location. This basic principle of customization was captured here as the objective to provide a system that gather information from users in relation to desired attractions, restaurants and other locations, and allow them to anonymously rate these locations based on pre-defined criteria such as quality of service, safety and so on. The system functions on mobile devices of the users and it deviated from any typical information that existed which would enable the users to input and maintain their own information. The system also allows the users to rate these attractions particularly based on their safety (the amount of criminal activity) aspects and other selected categories.

From the literature surveyed it is clear that there exists some research where mobile information systems been developed which allows users to retrieve place of interest based on location along with rating information in terms of service, Environment, Infrastructure and safety which is unique. There has also been research reported in Personal Information Systems where GPS being used towards selecting a location and also choosing the best route in real time. In none of the research except for the one developed by Stennet and Suresh, 2009 [2], Safety been taken as a criteria in retrieving points of Interest. But the system got some drawbacks as it possesses no GPS capability in particular towards navigation. Points of interest could not be automatically detected as the user travels. Route planning in this system could not be based on user defined attributes such as the safest route based on safety ratings. Lastly safety rating of place could be obtained only from user but not from police force. These drawbacks are mitigated in the Personal Mobile Information Systems developed in Android as Android possesses GPS features. These are explained in forthcoming section.

\section{Architecture Of Personal Mobile Information System in ANDROID}

The personal Mobile Information system in Android comprises of two types of users which are General User and Police user. The functionalities of users are given below:

\section{General User Application}

This is the application that the ordinary user would use. Its features include following

- Registration and Login of Users

The general user app allows first time users of the system to self-register. This involves the user setting up a user account by providing personal details including their full name, e-mail address and password. The information is then stored in a database and the password encrypted.

- Rating Point of Interest (POI)

This is one of the main functionality of the PMIS for general user application. It provides a user-friendly interface that allows one to share their experience with others via a rating system.

The ratings are categorized into the following:

i. Ambience

ii. Quality of service

iii. Cleanliness

iv. Safety

\section{- Display Average user Rating}

After the user has recorded their experience at Point of Interest (POI), the General user application automatically displays the average user rating for all POIs. As soon as the 
user goes into a category, the list of all POIs belonging to that category is displayed along with its respective average rating.

- Find POI on Map

Once the user has found POI, the general user application gives the user the option to find the location on a map. If the user selects the option, a route will be plotted from the user's current location to the POI. This annotation can significantly aid the user in finding their POI easily and more efficiently.

- Crime Proximity Alert

This is a key feature of the PMIS general user app. This feature allows the user to get early warnings/alerts about imminent dangers that exist en-route to the POI. In order to set these alerts, the application relies on the Police to log crime data via the PMIS police user app. A background process will load all crime events that are two (2) hours or less to the user's mobile device. The two hour criterion is used to restrict the amount of results from the crime data table. This will ensure that the most recent events are used to set alerts, and therefore are valid information for the user to consider en-route to the POI. When the user gets within proximity of any logged crime event, a notification will be generated in the form of a vibration and a $\log$ in the android notification list. The notification entry will show the type of crime and the address where it occurred.

\section{Police User Application}

The PMIS relies on the Police user to input and update crime-related information on specific locations. Once the data is entered into the system, it is deemed to be a confirmed crime event .This data is then exploited by the general user application in the form of proximity alerts. The Police User Application allows the user to do the following:

- Login User

In order for the Police user to access the PMIS, a user account will have to be created by the administrator. All requests to create new users for the Police would come from the appointed senior officer. This will ensure the integrity of the data by preventing any unauthorized user from accessing the PMIS.

- Log Crime Event

Once a crime is confirmed by the police, it is logged in the PMIS database as a crime event. The police are first required to select from a predefined list of crime situations that are applicable to the event. After this is done, the next requirement is to record the address of the crime that has occurred. Upon the completion of the required fields, the user has the option to save the information in two ways:

i. $\quad$ Save based on current location of the police - This save request option allows the police to record their current physical location using the GPS component of the device, which helps to ensure the integrity of data as it doesn't allow the police to manually enter coordinates. Once the app receives the coordinates via GPS a save request is issued.

ii. $\quad$ Save based on address of crime event- This save request option is best used if the police is not physically at the scene of a crime. When the option is selected the application will convert the address to coordinates using a geocoder feature within android. After receiving the coordinates this information is recorded with the two required fields (crime type and address).

- Update Police rating for POI

This option allows the police to update the safety rating of any POI in the system at any point in time. The rating is selected via a rating bar represented by stars from 1 to 5 . 
After submission this information will be available in the General user application labeled as police safety ratings.

\subsection{Architecture for Personal Mobile Information System}

Figure 1 gives a global view of the PMIS System architecture proposed. The system design starts with the users of the system which are the General User and the Police User.

The PMIS was designed this way to aid both users in performing specific tasks efficiently and accurately (e.g. the general user rating a POI or a police user logging a crime event), hence preserving the integrity of the PMIS information. To build confidence in the PMIS, the police application is justified mainly due to the sensitive nature of crime data generated by the Police. As such there needs to be a system that can build a reputation as a reliable source by guaranteeing the veracity of such information that is disseminated.

Similar to Stennet's design [2], the proposed system is user driven, meaning that the success of the system heavily relies on the users' maintenance of the data. Any information that needs to be submitted or requested from the PMIS will be done via the user's application in the form of an HTTP GET or POST sent over a mobile data connection. The request would be received by the application server running Apache. This connection is established in a background thread. The system is designed in this way because in mobile data connections, sometimes responses take a long time to either be sent or received. As a result, the user may have a bad experience with application's UI such as slow response time because the main UI thread is blocked.

When the application server has reliably received the connection from the user's application, it will establish a connection with the PMIS database server and execute stored procedures to either extract or submit information to the database. This proposed system uses MySQL as both the database server and database. The user interaction of system is shown in Figure 2 by means of use case diagram

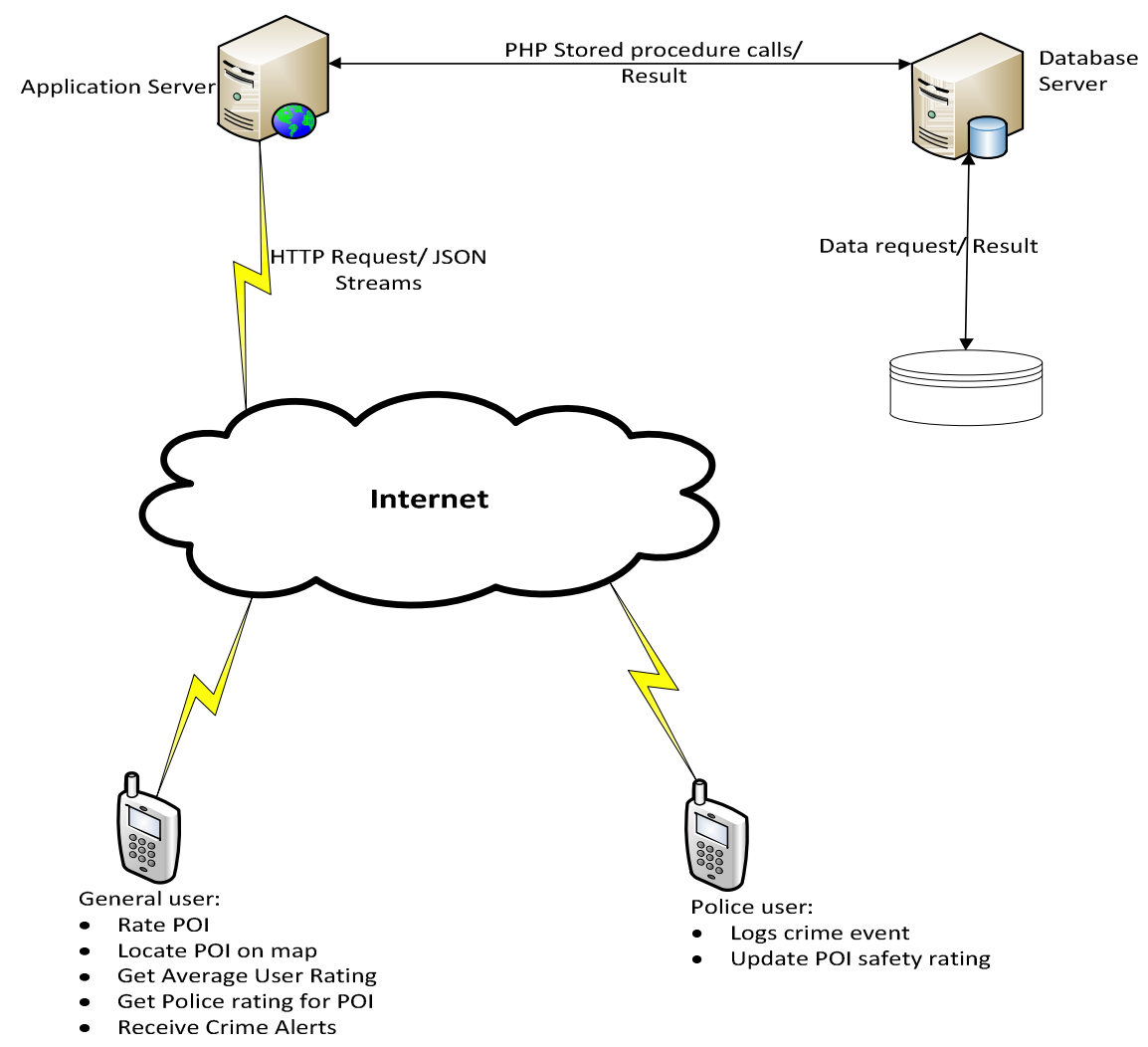

Figure 1 PMIS System Architecture 


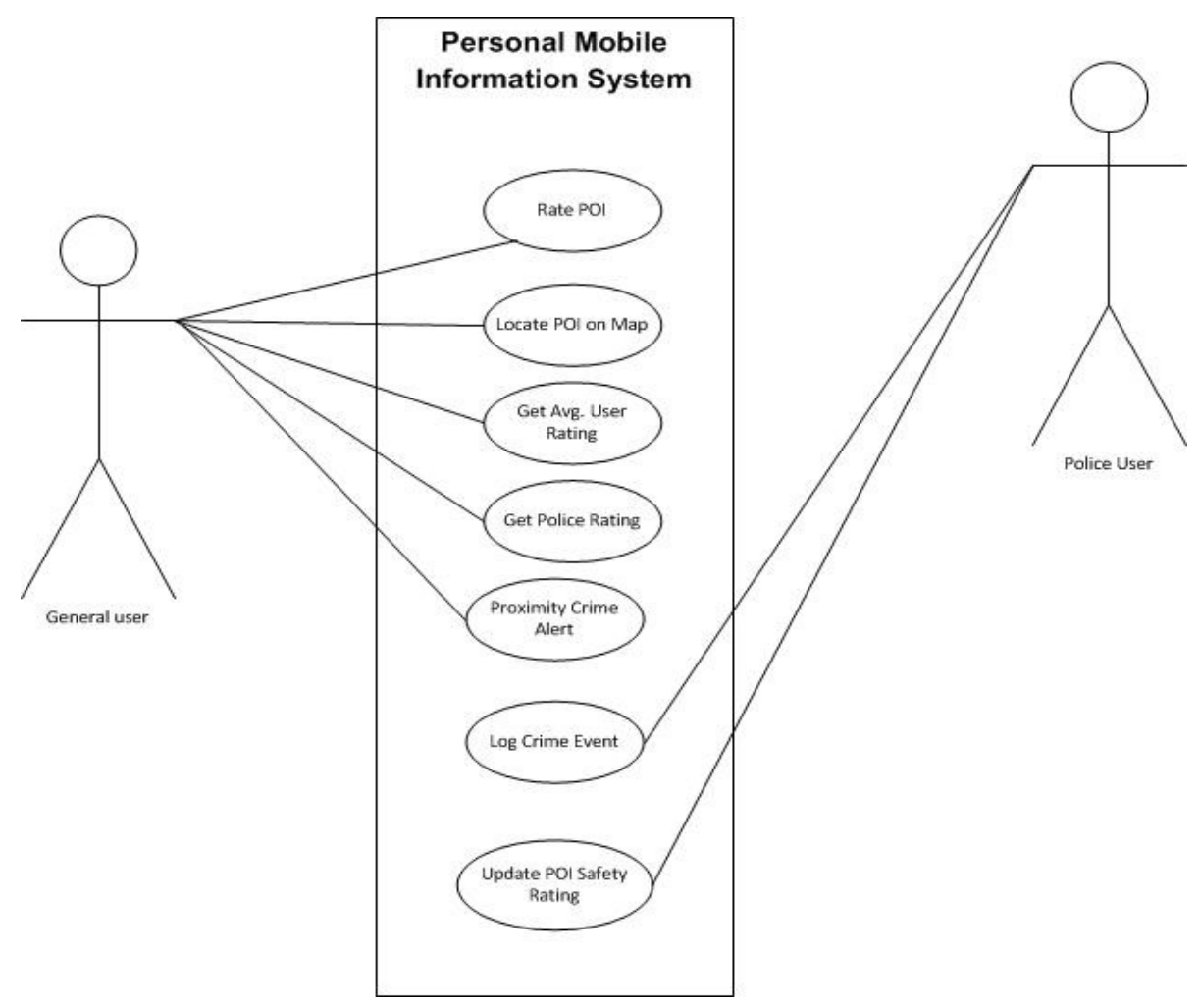

Figure 2 Use Case Diagram

The implementation of Personal Mobile Information System in Android been carried out using technologies like Android SDK [7][8] and AVD Manager [9], XAMPP Platform, Android 2.3.3, Php, Mysql and Eclipse IDE

\section{IMPLEMENTATION USING ANDROID}

The PMIS system consists of two users which are General and Police user. This Section here seeks to illustrate all the implemented major features of the General and police user application.

\subsection{General User Application}

On launching the general user application the user will be presented with a screen to enter their credentials to access the PMIS as shown in Figure 3. Once the user has successful been authenticated they will be presented with the main dashboard of options available to perform other operations.

If the user is new to the PMIS, they would be required to select the "click here to sign up now" label at the bottom of the screen as shown in Figure 4. Once this is executed, the user will be presented with a GUI as shown in Figure 4 to present the user's full name, email address and password. Once a user is authenticated and logged in as shown in Figure 3, the user will be presented with a screen of categories that group point of Interest (POI). The user would then select the option they desire as shown in Figure 5. When the user has selected their desired option based on the POI they are interested in, the general user app will access the PMIS database and load all the relevant information. While the information is loading the user will get a progress dialog indicating that the application is working in the background. Once the 
International Journal of Ambient Systems and Applications (IJASA) Vol.1, No.2, June 2013

progress bar is removed all details about point of Interest will be populated which includes user and police rating as shown in Figure 6.

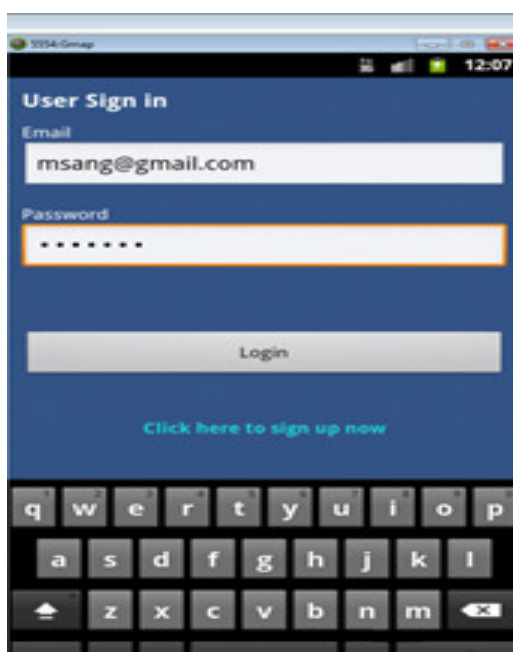

Figure 3 General User Login

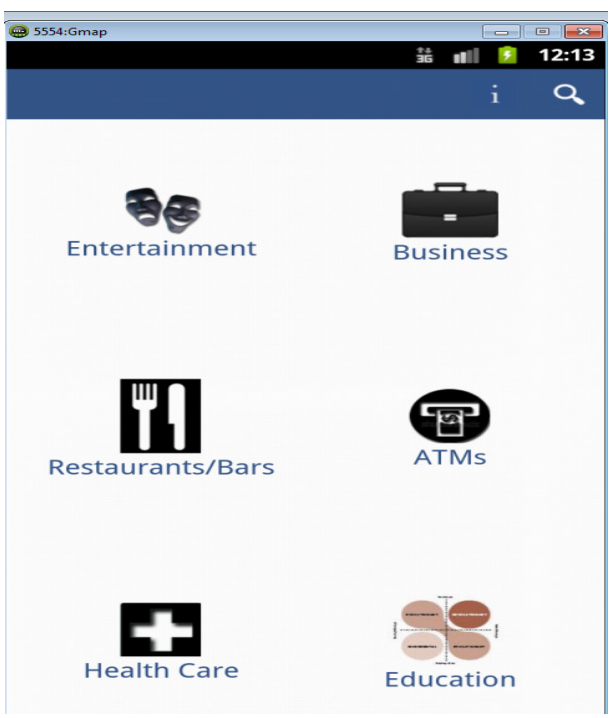

Figure 5 General User Application Category

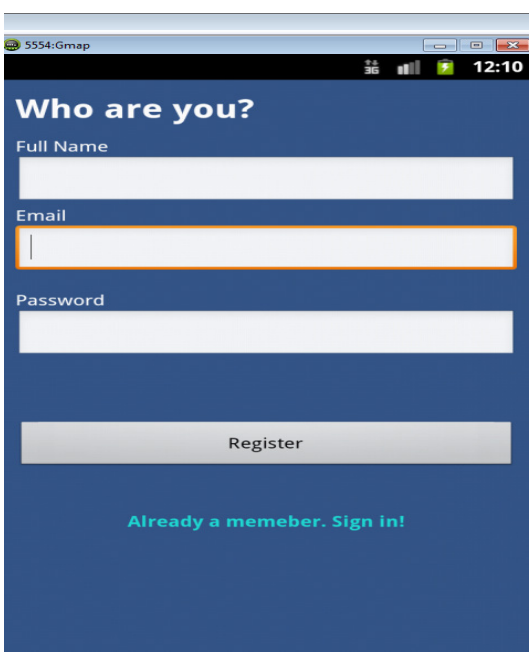

Figure 4 Registration of New User

\begin{tabular}{|c|c|}
\hline \multirow{2}{*}{ 5554:Gmap } & 40 回 23 \\
\hline & 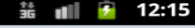 \\
\hline \multicolumn{2}{|c|}{ Entertainment Category } \\
\hline \multicolumn{2}{|l|}{ 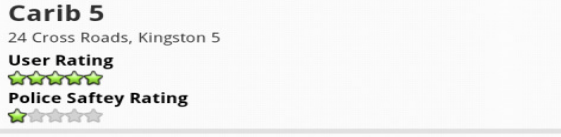 } \\
\hline \multicolumn{2}{|l|}{ 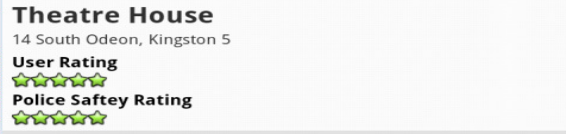 } \\
\hline \multicolumn{2}{|l|}{$\begin{array}{l}\text { Palace Cineplex } \\
23 \text { Barbican Drive, Kingston } 10 \\
\text { User Rating } \\
\text { Police Saftey Rating } \\
\text { Pind }\end{array}$} \\
\hline 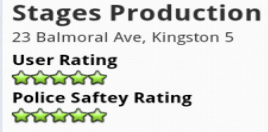 & \\
\hline
\end{tabular}

Figure 6 General User-Point of Interest

When the user clicks on a desired POI they will be given the option of either finding the POI on a map from their current location or to give the POI a rating based on their experience as shown in Figure 7. If the user select from the screen shown in Figure 8 the option to find location on a map, a GUI will be displayed with first, a turn by turn direction to find the location as shown in Figure 9. On clicking the checker icon at the bottom of the directions another GUI with a route plotted from their current location to the destination (POI) as shown in Figure 10. 


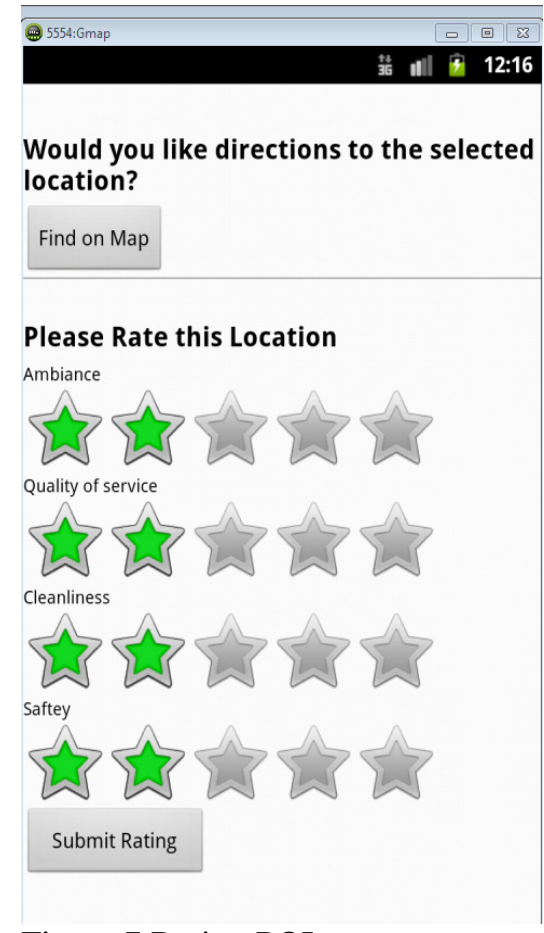

Figure 7 Rating POI

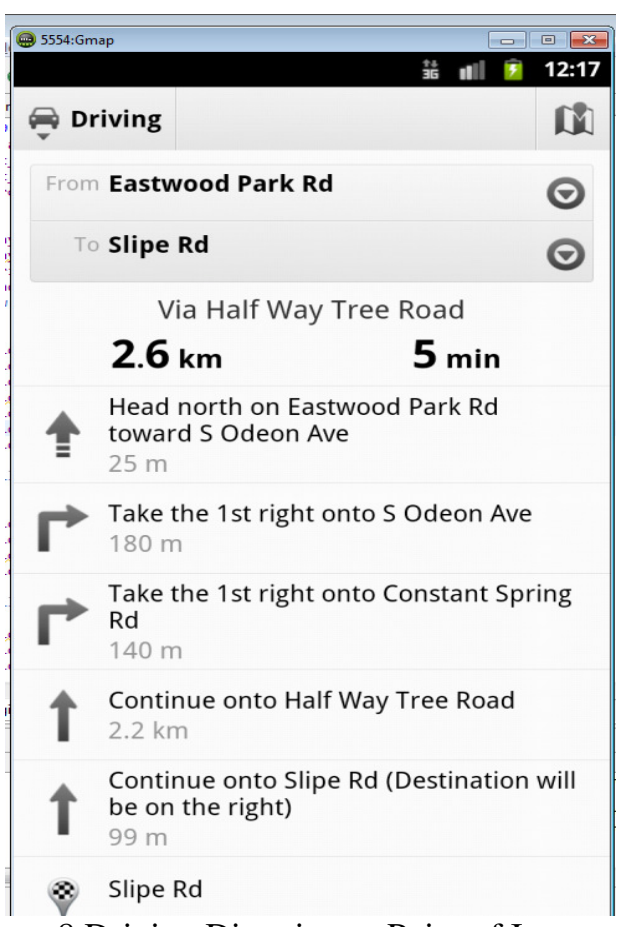

Figure 8 Driving Direction to Point of Interest

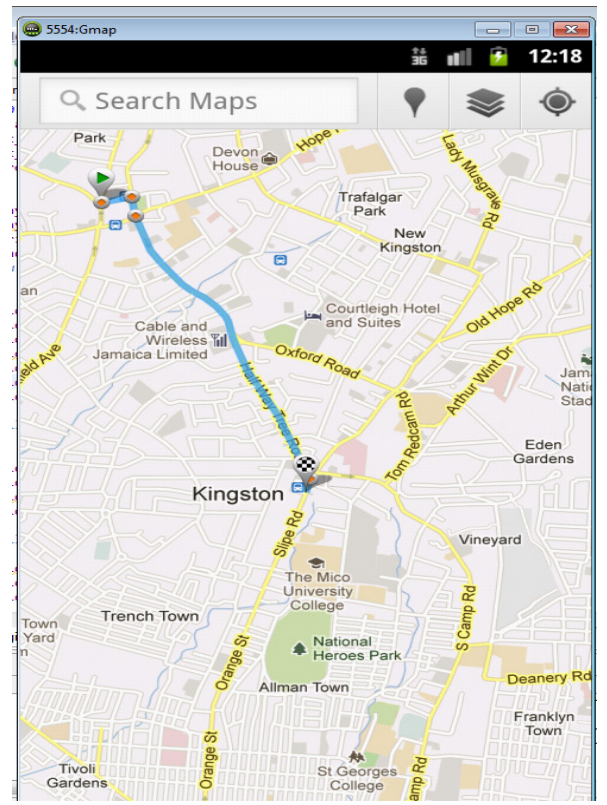

Figure 9 Map Route to POI from Current Location

If the user opts to input their experience via rating POI as shown in Figure 10, on pressing the "submit Rating" button they would be presented with a progress dialog that indicates them that their ratings are being pushed to the PMIS database as shown in Figure 10. After the progress dialog clears the rating will be re-calculated and the update displayed. This is a very important feature of the PMIS general user application. A major aim of this PMIS system is to assist the user in finding their POI in the safest possible manor. The application without the knowledge of 
International Journal of Ambient Systems and Applications (IJASA) Vol.1, No.2, June 2013

the user, loads all crime events that have been logged by the police that are less than two 2 hours old and creates a waiting crime proximity alert. Once the application detects that the user is within proximity of a logged crime event it then gives an alert in the form of a phone vibration and a $\log$ in the Android OS notification list. Figure 11 shows how the notification would be presented to the user. The type of crime and address will be displayed to user in order for them to know where exactly to avoid

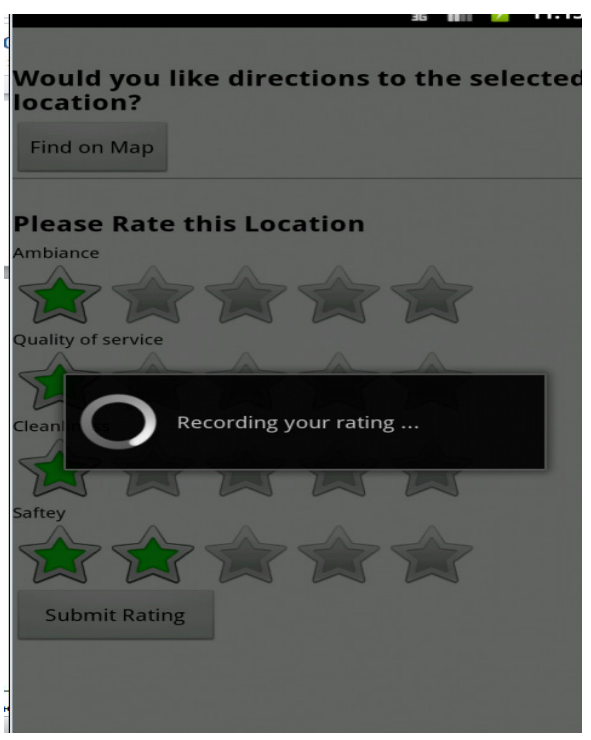

Figure 10 Rating Recording

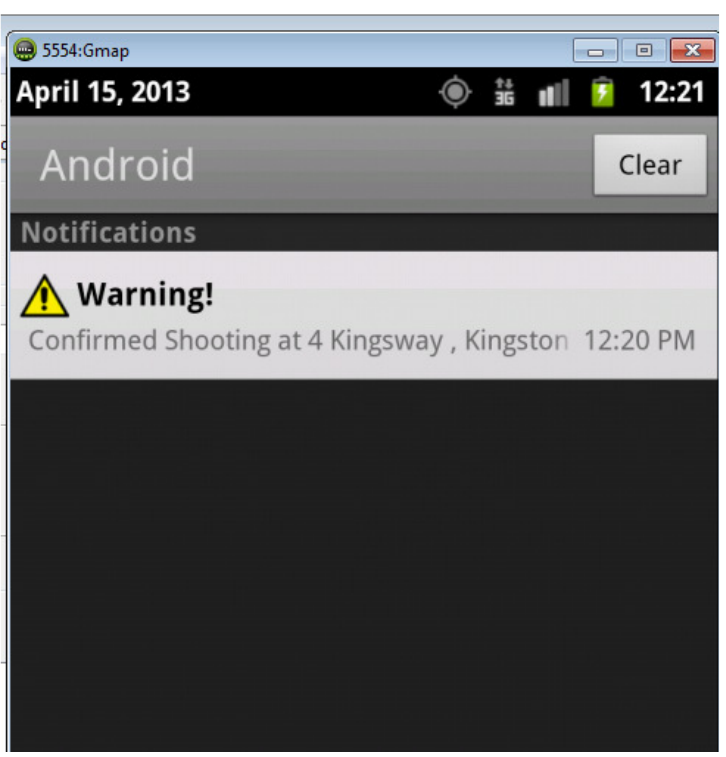

Figure 11 General Proximity Crime Alert

\subsection{Police User Application}

On launching the Police user application the user will be presented with a form to enter their credentials to access the PMIS as shown in Figure 11. Once the police have been authenticated by the Police user application, they will be presented with the screen as shown in Figure 12. This gives police the option to either log a new crime event that has occurred or update the safety rating for POI.

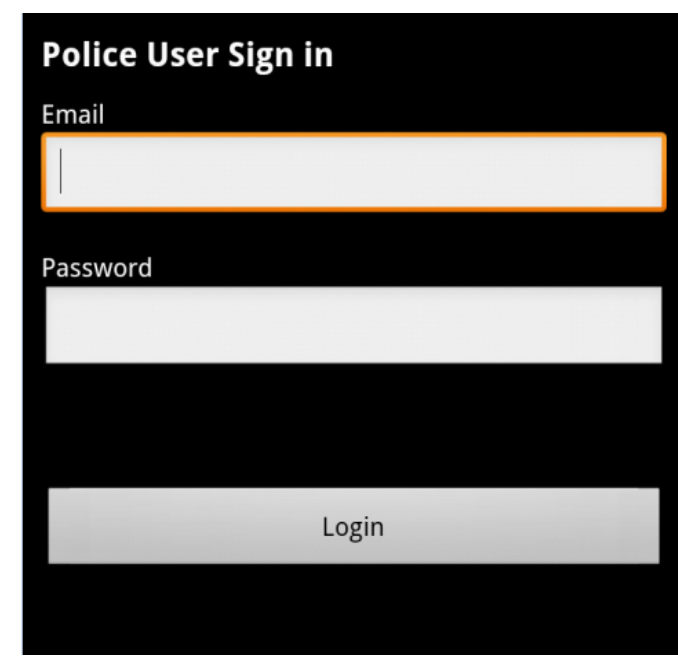

Figure 11 Police Logon Credentials

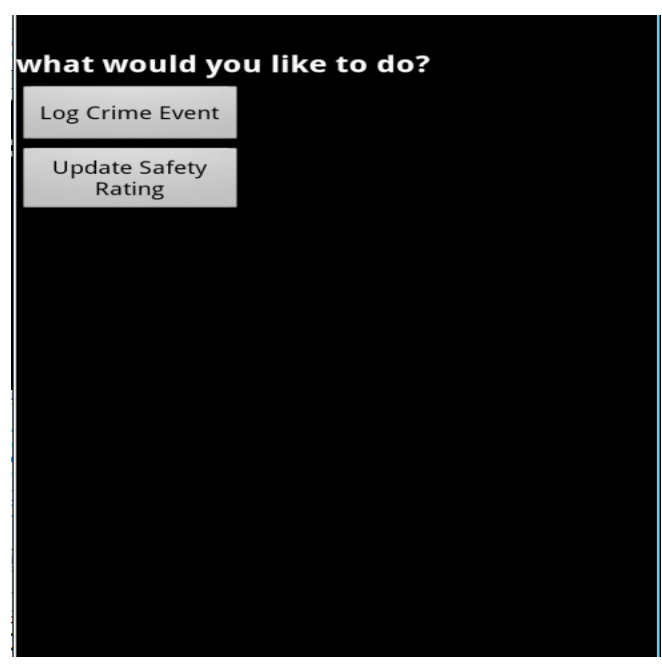

Figure 12 Police User option Page 
International Journal of Ambient Systems and Applications (IJASA) Vol.1, No.2, June 2013

If the police select the option to "log a crime event" they will be presented with a GUI as shown in Figure 13. They are then required to select crime type and enter the address where the crime occurred. The crime types are displayed as predefined list of crimes available for the police to select as shown in Figure 14. This list can be altered by the administrator of the PMIS, once requested by the appropriate authority. After the crime type is entered, the police user is then required to enter the address of the crime to be logged shown in Figure 15. When the user has entered the required fields it should be submit the information to be saved in the PMIS database. There are two ways that the information can be saved. If the police are at the scene of the crime, they should use the "Save based on the current coordinate" option as shown in Figure 16. This is designed to allow the application to automatically get the current coordinates and save it along with the required info (crime type and address). The other option is to "save based on the address entered". This option is used by the police when they are not at the scene of a crime. The application will automatically convert the address entered to a coordinate and save this info along with the required fields as shown in Figure 17. Once this button as shown in Figure 17 is pressed the application will automatically convert the address entered in Figure 15 to coordinates and save this info along with the required fields. When the police select the correct option based on the situation being dealt with, a message will be displayed showing the coordinates that were pushed to the PMIS database as shown in Figure 18.This information can then be exploited by the general user application.

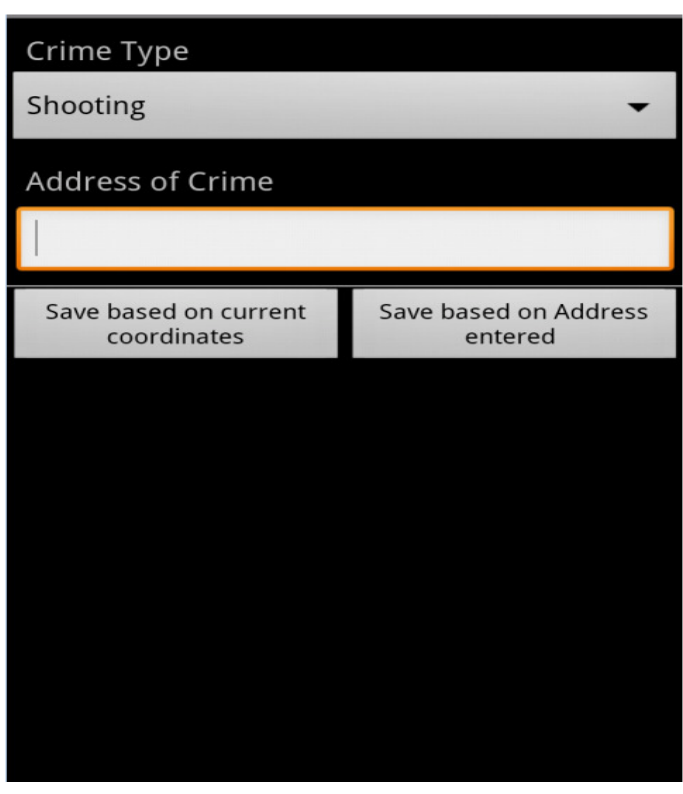

Figure 13 Police Crime GUI

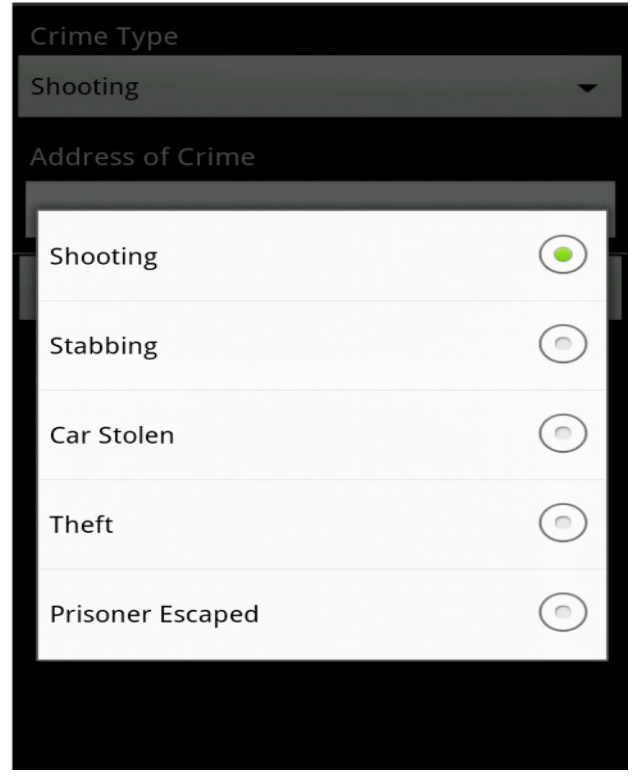

Figure 14 Predefine Crime Types 
International Journal of Ambient Systems and Applications (IJASA) Vol.1, No.2, June 2013

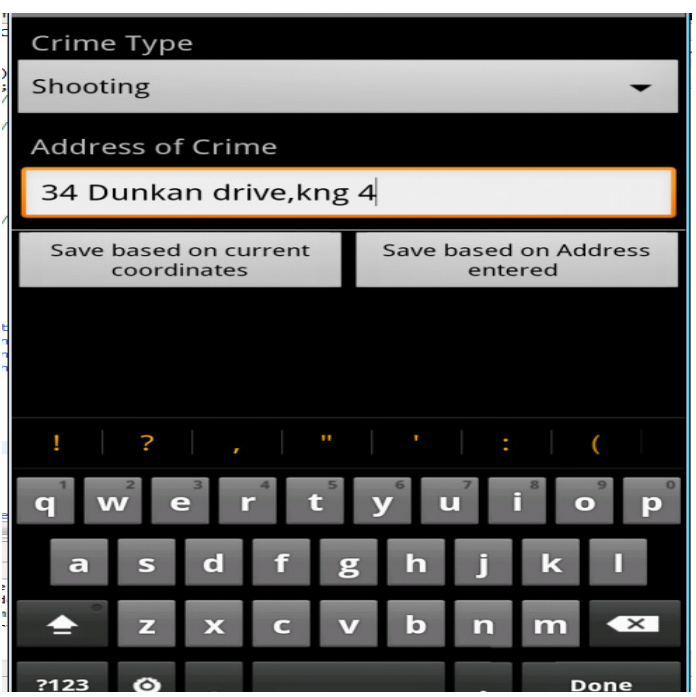

Figure 15 User entering address

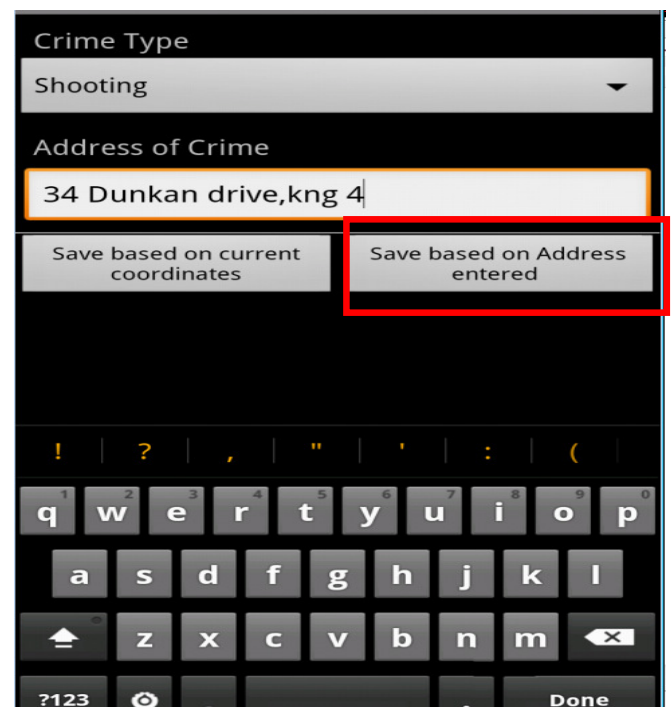

Figure 17 Crime Scene Address

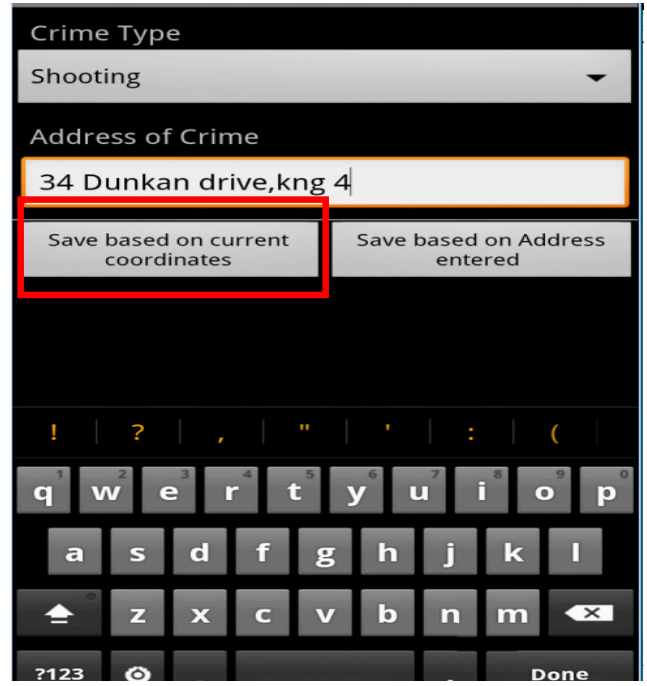

Figure 16 Crime Scene Address Saved

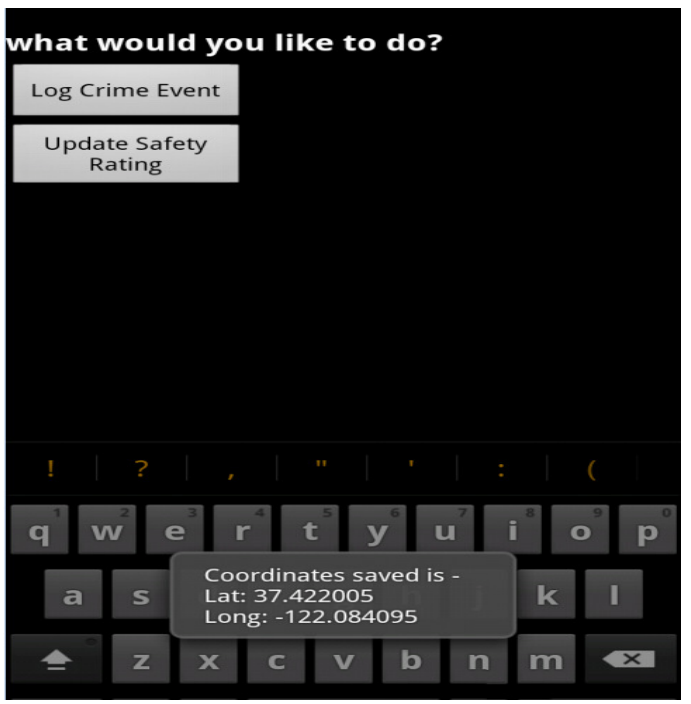

Figure 18 Crime Scene Address Coordinates

If the police user selects the option to update safety ratings they will be presented with a GUI showing all the POI within the system with the respective police rating as shown in Figure 19. If a police user opts to update a POI police rating for say "Carib 5", they would need to select the specific POI as shown in Figure 20. When the specific POI has been selected the user will be shown the GUI illustrated in Figure 21. This page allows the police to update the safety rating for a POI based on what they have observed at the location over a particular time. I.e. if Police recognize a trend they would use this method to make citizens aware. E.g. Car theft in POI parking lot or petty crime outside POI location. When the rating is selected from the rating bar, the police would then press submit button to finalize the update. A progress dialog would then be displayed as shown in Figure 22 indicating that the app is working in the background to push the updates to that PMIS database. After the progress dialog clears, the police rating for the POI will be updated and the updated values reflected to the user in the GUI shown in Figure 23. 
International Journal of Ambient Systems and Applications (IJASA) Vol.1, No.2, June 2013

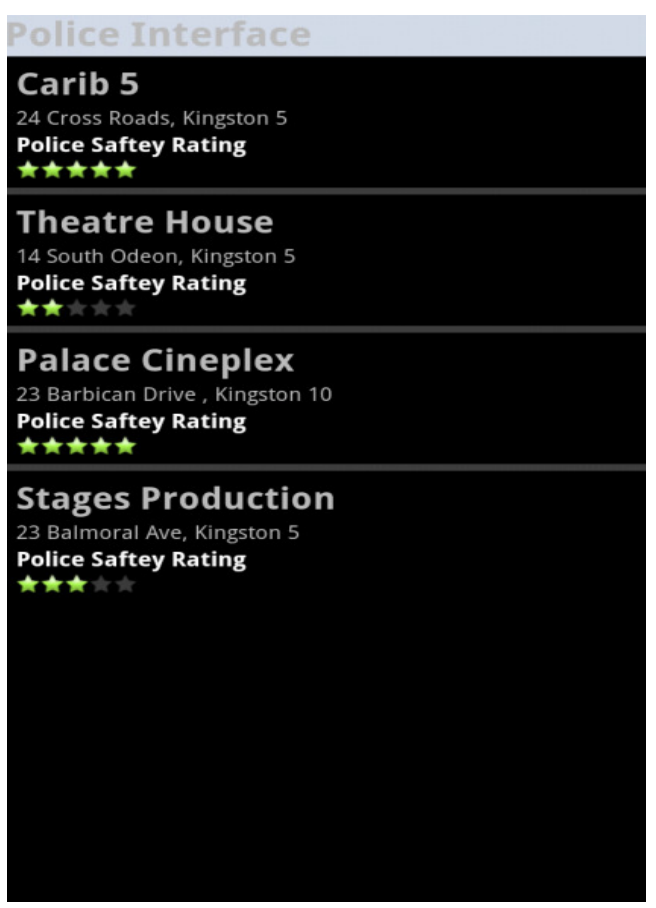

Figure 19 POI- Police Safety Rating

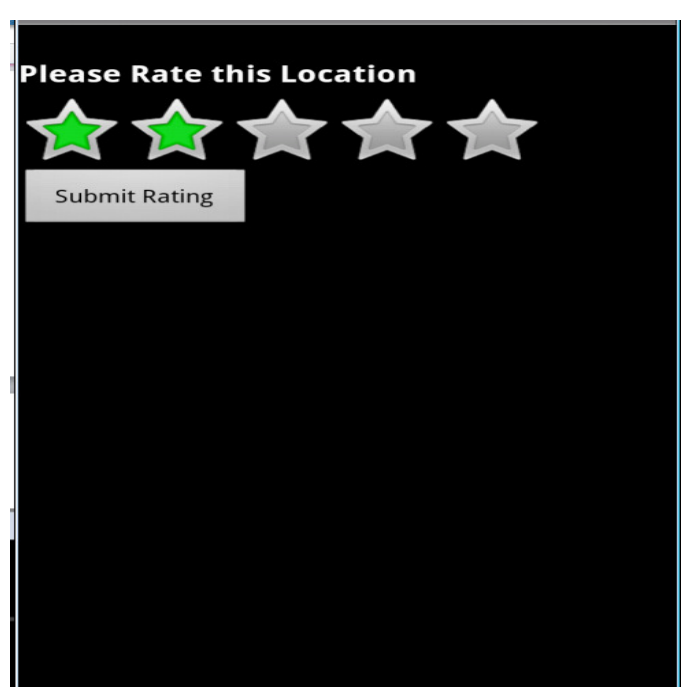

Figure 21 Police Rating POI

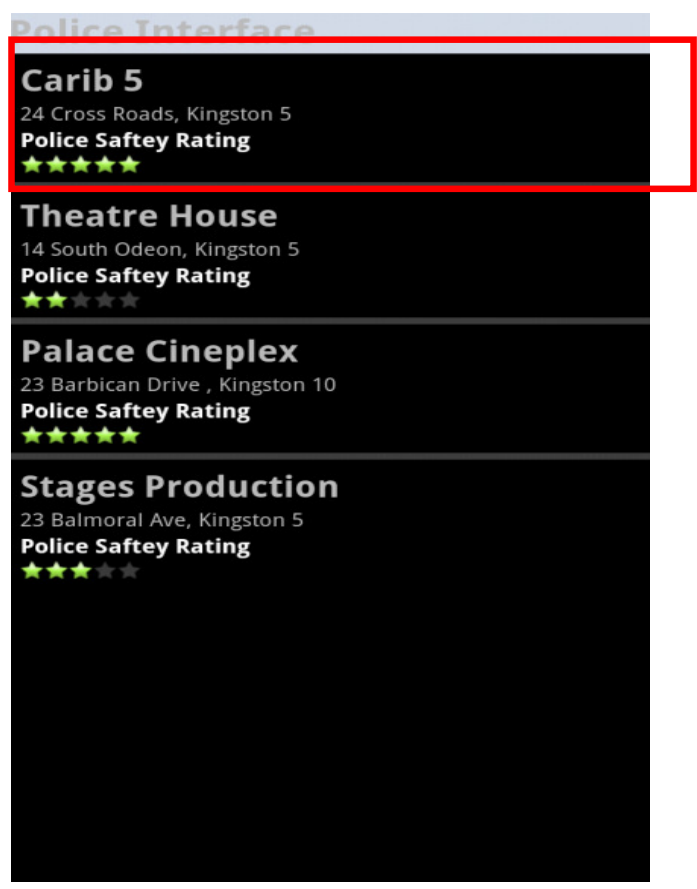

Figure 20 Selecting Carib 5 POI

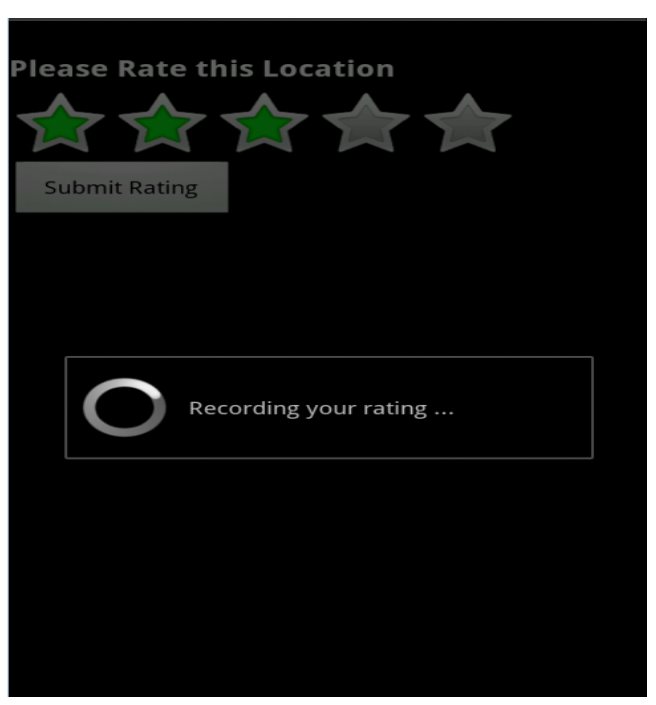

Figure 22 Progress dialog 
International Journal of Ambient Systems and Applications (IJASA) Vol.1, No.2, June 2013

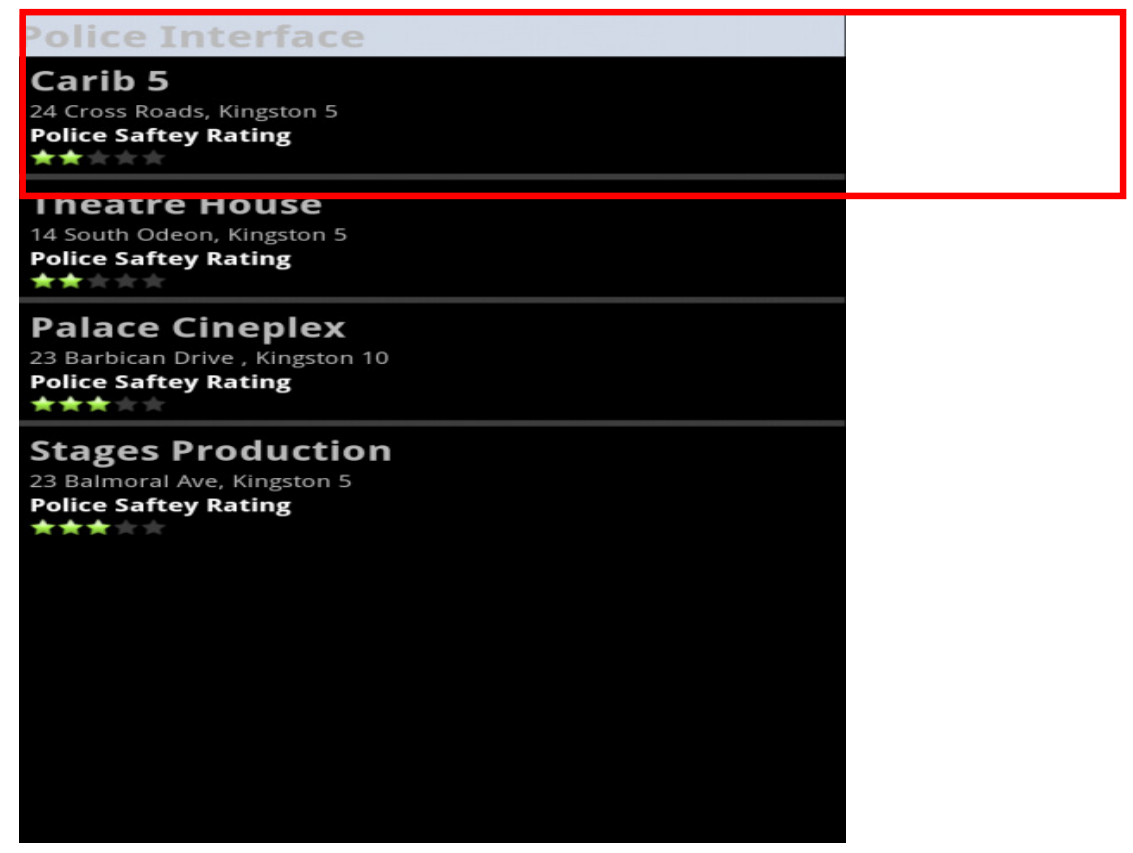

Figure 23 Updated POI Police Rating

\section{CONClusion \& Future Work}

The need for such a system was established by outlining the challenges of Mobile Information Systems, which underscored increasing demand for customization as critical to providing more functional information to users. Moreover, it was highlighted that due to travel patterns and the availability of modern transportation facilities, many persons are looking to location based services as a fixture on mobile applications to fulfill their technology needs.

The researcher therefore, explored the mechanics of location based services using GPS technology and the use of proximity alerts or early warning signals in different scenarios to enhance the user experience. An outline was given of the various applications or diverse uses of location based services across sectors, and its growing popularity in the mainstream technology market. The social implication of mobile information systems was also looked at within the context of law enforcement. Particularly, if mobile applications are used by the police to keep the public informed of criminal activities it would create a more conscious and proactive citizenry in safeguarding their own well-being while at the same time restoring confidence in police personnel. So to conclude the Personal Mobile Information System is implemented with a General User and Police User Application. The separation is attributed to the type of data that is inputted and the level of authorization that is required for both. This model establishes the feasibility of combining two different user groups under one system to enhance the information that is provided. Furthermore, we have identified cases and situations in which our system would be beneficial. We are confident that the ideas researched in this research will be of benefit to others interested in this field of study and will assist in the advancement of information systems and in particular mobile information systems.

In future system is to allow the General user of the PMIS to also be able to log crime events. The reality is that the Police will not always be around to confirm all crimes; hence, there are many crimes that from the system's perspective would have never happened. Another level of exploitation that can occur with this crime information is exporting the data in format that can be seen visually on a map. This information could be very valuable to the police in there crime fighting efforts as they would get a visual representation of all crime that have been logged. 
International Journal of Ambient Systems and Applications (IJASA) Vol.1, No.2, June 2013

Therefore, from just looking at the map one can see the area that crimes are concentrated. As a result, the Police authorities can make more informed decision in terms of where they should allocate their resources. Last but not least Police Safety rating details should change automatically/online based on incident reported by police authorities in addition to updating point of interest by police user based on incident.

\section{REFERENCES}

[1.] Khosrow-Pour, M. (2006). Emerging Trends and Challenges in Information Technology Management. New York: IGI Global.

[2.] Stennet, D. \& Suresh, S. (2009). Applications of Personal Mobile Information Systems. Proceedings of 2nd ACM International conference on Interaction Sciences: Information Technology, Culture and Human (ICIS 09), Seoul, Korea. PP. 592-598

[3.] Setten, M. \& Tokmakoff, H. (n.d.). Designing Personalized Information Systems- A Personal Media Center Retrieved May 4, 2012 from website: http://www.di.unito.it/ liliana/UM01/vanSetten.pdf

[4.] Alatalo, T., et al., (2001). Mobile Information Systems. Retrieved on April 25, 2013 from http://owla.oulu.fi/publications/syte-seminar-final.pdf

[5.] Yang, F. \& Wang, Z., (2009). A Mobile Location-based Information Recommendation System Based on GPS and WEB 2.0 Services. ISSN: 1109-2750. Issue 4, Volume 8. Retrieved April 27, 2013 from http://wseas.us/e-library/transactions/computers/2009/29-185.pdf

[6.] Kushwaha, A. and Kushwaha, V. (2011) Location Based Services using Android Mobile Operating System. International Journal of Advances in Engineering and Technology, Vol.1(1). Pp. 14-20.

[7.] ADT Plug-in. Retrieved April 30, 2013 from website: http://developer.android.com/tools/sdk/eclipse-adt.html

[8.] Android Software development. Retrieved April 30, 2013 from http://en.wikipedia.org/wiki/Android_software_development

[9.] AVD Manager. Retrieved April 30, 2013 from website: http://developer.android.com/tools/help/avd-manager.html

\section{Authors}

Duarte-Rhian Nicely holds Bachelor's degree in Computer Science in 2007 and currently pursuing Master's degree in Computer science from University of since 2011. He is currently employed as Network systems Administrator in Digicel. He got skills in Perl, Java and Android programming. His current research interests are mainly in Networking, Mobile Computing.

Prof.(Dr) Suresh. Sankaranarayanan is currently an Associate Professor, Department of Computer \& Information Systems, Institute of Technology, Brunei (ITB - A technological university) and also Visiting Professor, Department of Computing, University of WestIndies, Kingston, Jamaica. He has supervised around 30 research students leading to M.Sc, ME, M.Phil and M.S degrees and currently supervising students leading to M.sc, M.phil and Ph.d respectively. He has got to his credit, as on date, about 50 fully refereed research papers published in the Proceedings of major IEEE international conferences, as Book Chapters and in International Journals. His current research interests are mainly towards 'Mobile and Ubiquitous Computing - Wireless Sensor Networks, Mobile Commerce, Intelligent Agents' used in the Health, Commercial and Engineering sectors. 